\title{
N-myc downstream-regulated gene 1 promotes oxaliplatin- triggered apoptosis in colorectal cancer cells via enhancing the ubiquitination of Bcl-2
}

\author{
Xiao Yang ${ }^{1,2, *}$, Fan Zhu ${ }^{1,2, *}$, Chaoran Yu ${ }^{1,2, *}$, Jiaoyang Lu ${ }^{1,2}$, Luyang Zhang ${ }^{1,2}$, Yanfeng \\ Lv $^{3}$, Jing Sun ${ }^{1,2}$ and Minhua Zheng ${ }^{1,2}$ \\ ${ }^{1}$ Department of General Surgery, Ruijin Hospital, Shanghai Jiao Tong University, School of Medicine, Shanghai 200025, \\ P.R.China \\ ${ }^{2}$ Shanghai Minimally Invasive Surgery Center, Ruijin Hospital, Shanghai Jiao Tong University, School of Medicine, Shanghai \\ 200025, P.R.China \\ ${ }^{3}$ Department of Colorectal Surgery, Second Hospital of Shandong University, Shandong University, Jinan 250000, P.R.China \\ *These authors have contributed equally to this work \\ Correspondence to: Minhua Zheng, email: ZhengMHrihospital@163.com \\ Jing Sun, email: jingsun1982@sina.cn \\ Yanfeng Lv, email: yanfenglv1979@sina.com \\ Keywords: apoptosis, colorectal cancer, neoadjuvant chemotherapy, NDRG 1, BCl-2 \\ Received: November 15, $2016 \quad$ Accepted: April 14, $2017 \quad$ Published: May 09, 2017 \\ Copyright: Yang et al. This is an open-access article distributed under the terms of the Creative Commons Attribution License 3.0 \\ (CC BY 3.0), which permits unrestricted use, distribution, and reproduction in any medium, provided the original author and source are \\ credited.
}

\section{ABSTRACT}

N-myc downstream-regulated gene1 (NDRG1) has been identified as a potent tumor suppressor gene. The molecular mechanisms of anti-tumor activity of NDRG1 involve its suppressive effects on a variety of tumorigenic signaling pathways. The purpose of this study was to investigate the role of NDRG1 in the apoptosis of colorectal cancer (CRC) cells. We first collected the clinical data of locally advanced rectal cancer (LARC) patients receiving oxaliplatin-based neoadjuvant chemotherapy in our medical center. Correlation analysis revealed that NDRG1 positively associated with the downstaging rates and prognosis of patients. Then, the effects of overexpression and depletion of NDRG1 gene on apoptosis of colorectal cancer were tested in vitro and in vivo. NDRG1 over-expression promoted apoptosis in colorectal cancer cells whereas depletion of NDRG1 resulted in resistance to oxaliplatin treatment. Furthermore, we observed that $\mathrm{Bcl}-2$, a major anti-apoptotic protein, was regulated by NDRG1 at post-transcriptional level. By binding Protein kinase Ca (PKCa), a classical regulating factor of $\mathrm{BCl}-2$, NDRG1 enhanced the ubiquitination and degradation of Bcl-2, thus promoting apoptosis in CRC cells. In addition, NDRG1 inhibited tumor growth and promoted apoptosis in mouse xenograft model. In conclusion,NDRG1 promotes oxaliplatin-triggered apoptosis in colorectal cancer. Therefore, colorectal cancer patients can be stratified by the expression level of NDRG1. NDRG1-positive patients may benefit from oxaliplatin-containing chemotherapy regimens whereas those with negative NDRG1 expression should avoid the usage of this cytotoxic drug.

\section{INTRODUCTION}

Preoperative chemoradiation therapy (CRT) followed by total mesorectal excision (TME) has been currently considered as the standard treatment strategy for locally advanced rectal cancer (LARC) [1-3]. However, the optimal type of neoadjuvant therapy regimen is still unclarified. Several randomized trials comparing the efficacy and toxicities of CRT with or without oxaliplatin (L-OHP), as the preoperative treatment for locally advanced rectal cancer have been reported [4-7]. Although the results were inconsistent, oxaliplatin was still a reasonable candidate for inclusion into 
neoadjuvant chemotherapy regimens, which was further evidenced by studies demonstrating that oxaliplatin was able to induce apoptotic cell death in colorectal cancer (CRC) cells $[8,9]$. However, the mechanisms by which oxaliplatin trigger death signal in cancer cells have not been fully defined yet.

Apoptosis is a morphologically and molecularly distinct form of programmed cell death. This conserved cellular suicide program is initiated either 'intrinsically' [10, 11] through cellular stress that impinge on the mitochondria or 'extrinsically' $[12,13]$ from extracellular ligands that activate death receptors at the cytomembrane. One of the most important advances in cancer research is the recognition that apoptosis is crucially involved in the regulation of tumor formation and also critically determines chemotherapy treatment response [12, 14, 15]. Thus, understanding of the molecular events that regulate apoptosis in response to anticancer chemotherapy, and how cancer cells evade apoptotic death provides novel insights for a more rational approach to develop molecular targeted therapies for combating cancer.

$\mathrm{N}$-myc downstream-regulated gene $1(N D R G 1)$ plays a potent role in modulating metastatic ability in multiple types of solid tumor including CRC $[16,17]$, breast cancer $[18,19]$ and prostate cancer [20, 21]. Also, NDRG1 has been linked to many cellular processes including cell cycle, apoptosis, and cellular differentiation [22-26]. Plenty of studies indicate that over-expression of $N D R G 1$ is able to inhibit the invasion and metastasis of CRC. The molecular mechanism this anti-tumor activity involves its suppressive effects on several tumorigenic signaling pathways such as Wnt [27, 28], phosphatidylinositol 3-kinase (PI3K) [29, 30] and transforming growth factor- $\beta$ (TGF- $\beta$ ) [31] pathway. Moreover, our previous work revealed a significant inverse correlation of NDRG1 expression with tumor stage, differentiation status and metastasis in CRC patients, suggesting the clinical significance of NDRG1[32]. To date, however, the underlying mechanism by which NDRG1 affects apoptosis has not been fully elucidated. Hence, the specific functions of NDRG1 in apoptosis need to be further investigated.

\section{RESULTS}

\section{NDRG1 positively correlated to the downstaging rate and prognosis of $\mathrm{LARC}$ patients receiving neoadjuvant chemotherapy}

A total of 97 LARC patients were enrolled into our study. Colonoscopy was performed on each patient to validate the diagnosis. After 2 cycles of chemotherapy and subsequent surgical resection, patients were divided into downstaging or no-downstaging group according to the pathological staging results. Sixteen patients were randomly selected in each group. To evaluate the potential effect of NDRG1 on the efficacy of oxaliplatin-based chemotherapy, total RNA was extracted from cancer tissues and subjected to reverse transcription-polymerase chain reaction (RT-PCR). As shown, $N D R G 1$ transcript levels were significantly higher in cancer tissues from downstaging patients relative to those from nodownstaging ones (Figure 1A). Moreover, higher expression of NDRG1 in downstaging group was further confirmed at the protein level by western blots (Figure 1B). A tissue microarray containing specimens from all enrolled patients was analyzed by immunohistochemistry (IHC) (Figure 1C). In downstaging group, the positive expression of NDRG1 was detected in 39 cases $(67.2 \%)$, whereas only 18 cases (46.1\%) showed positive signal in no-downstaging group $(R$ $=0.210, P=0.039$, Table 1$)$. The detailed clinical information of each patient was listed in supplementary Table 1.

To further investigate the clinical significance of NDRG1 in CRC, we analyzed the possible correlation between NDRG1 expression and clinicopathologic variables (Table 2). Our data showed a significant inverse correlation between NDRG1 and tumor size $(R=-0.355$, $P=0.001)$, local invasion $(R=-0.318, P=0.002)$, lymphatic invasion $(R=-0.287, P=0.005)$ and TNM stage $(R=-0.287, P=0.005)$. Moreover, Kaplan-Meier analysis revealed that patients in the NDRG1 negative group $(\mathrm{n}=40)$ had a significantly poorer overall survival than those in the NDRG1 positive group ( $\mathrm{n}=57$; logrank $=10.37 ; P=0.001$; Figure 1D). Additionally, NDRG1 positive expression was associated with a longer disease-free survival time (log-rank $=9.974, P=0.002$, Figure 1E). These findings suggested that NDRG1 positively correlated to the downstaging rate of LARC patients receiving neoadjuvant chemotherapy. Moreover, NDRG1 might function as a potential prognostic marker.

\section{NDRG1 was necessary for oxaliplatin-triggered apoptosis}

To gain insight into the mechanisms of significant tumor regression in NDRG1-positive patients, we detected altered activities in several apoptotic pathways via a pathscan array using protein extracted from selected specimens. As shown, after two cycles of chemotherapy, the protein levels of P53, cleaved-caspase-3, and cleavedPARP were dramatically elevated in downstaging group (Figure 2A), indicating that the remarkable tumor regression in downstaging patients was due to substantial apoptosis induced by oxaliplatin. Western blot was then performed to analyze several apoptosis regulating factors. Intriguingly, upon the increase of NDRG1, a loss of Bcl-2 protein was detected in specimens from downstaging group while protein levels of other molecules stayed stable (Figure 2B and Supplementary Figure 1A), suggesting NDRG1 might promote apoptosis via targeting Bcl-2, a classical potent apoptosis suppressor. To investigate the role of NDRG1 in the apoptotic procedure, we generated HCT116NDRG1 cells stably expressing human NDRG1 and HCT116shNDRG1 cells depleted of NDRG1. The magnitude of apoptosis was measured with western blots. As shown, significant higher levels 
of cleaved-caspase-3 and cleaved-PARP were detected in HCT116NDRG1 cells (Figure 2C). In contrast, silencing of NDRG1 resulted in remarkable blockage of apoptosis (Figure 2C). Similar results were also observed in SW620 cells (Figure 2D). Moreover, the apoptosis induced by $N D R G 1$ was potentiated by oxaliplatin. After oxaliplatin treatment, the protein levels of cleaved-caspase-3 and -PARP in HCT116- and SW620NDRG1 cells were drastically elevated compared to those untreated whereas control cells showed moderate elevation (Figure 2C, 2D and Supplementary Figure 1B, 1C). Additionally, shNDRG1 cells showed negligible signal of cleaved-caspase- 3 and

A
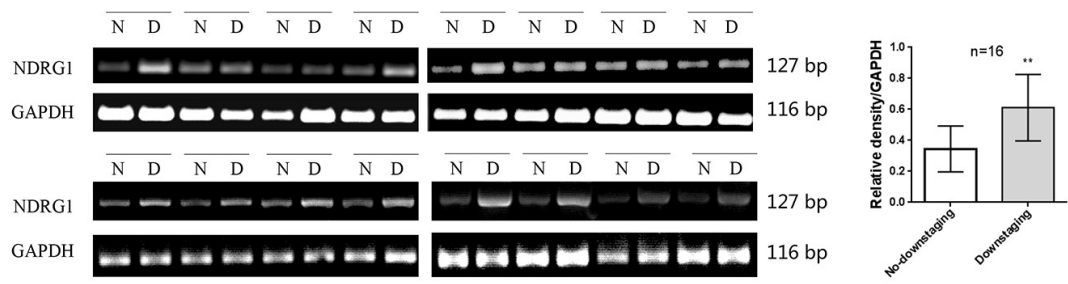

$\mathrm{B}$

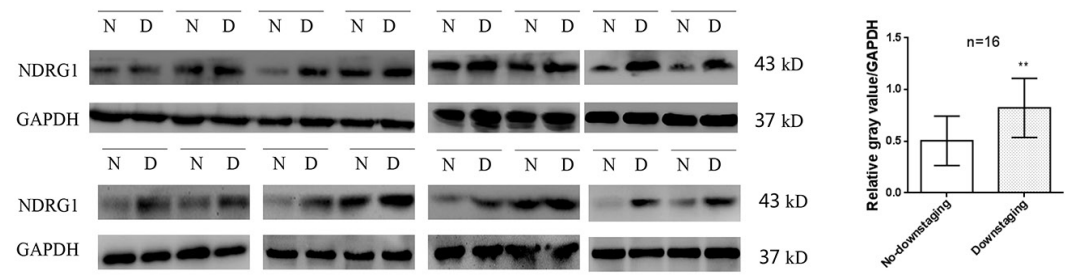

C
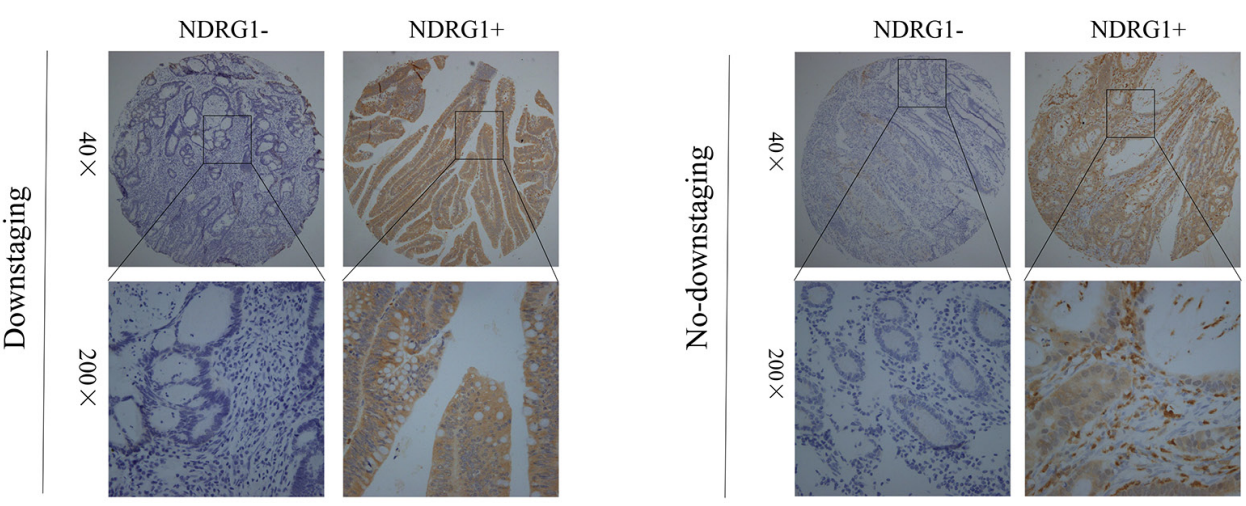

$\mathrm{D}$

$\mathrm{E}$


Figure 1: Expression of NDRG1 and its clinical significance in LARC patients. (A) RT-PCR showing $N D R G 1$ mRNA levels in 16 selected samples from downstaging and no-downstaging group respectively. Samples were selected by random numbers generated with SAS software. (B) Western blot analysis of NDRG1 expression in selected CRC samples. (C) NDRG1 protein levels in tissues from patients of downstaging and no-downstaging groups were measured with IHC staining. (D, E) CRC patients with negative expression of NDRG1 presented poorer overall survival (D) and disease free survival (E) compared with those with positive expression of NDRG1. Bars indicated SD. *, $P<0.05, * *, P<0.01$. 
Table 1: Relationship between NDRG1 expression and response to neoadjuvant chemotherapy

\begin{tabular}{|c|c|c|c|c|}
\hline & \multirow{2}{*}{$\begin{array}{l}\text { Case } \\
\mathbf{n}=97\end{array}$} & \multicolumn{2}{|c|}{ Response to chemotherapy } & \multirow[t]{2}{*}{$P$ value } \\
\hline & & Downstaging & No-downstaging & \\
\hline NDRG1-positive & 57 & 39 & 18 & 0.039 \\
\hline NDRG1-negative & 40 & 19 & 21 & \\
\hline
\end{tabular}

Table 2: Relationship between NDRG1 and clinicopathologic variables

\begin{tabular}{|c|c|c|c|c|}
\hline \multirow[t]{3}{*}{ Variable } & \multirow{3}{*}{$\begin{array}{l}\text { Case } \\
\mathrm{n}=97\end{array}$} & \multicolumn{2}{|c|}{ NDRG1 expression } & \multirow[t]{2}{*}{$P$ value } \\
\hline & & Positive & Negative & \\
\hline & & $\mathbf{n}=\mathbf{5 7}$ & $\mathrm{n}=\mathbf{4 0}$ & \\
\hline Age (years) & & & & 0.520 \\
\hline$\leq 65$ & 52 & 29 & 23 & \\
\hline$>65$ & 45 & 28 & 17 & \\
\hline Gender & & & & 0.119 \\
\hline Male & 72 & 39 & 33 & \\
\hline Female & 25 & 18 & 7 & \\
\hline ECOG performance & & & & 0.183 \\
\hline 0 & 68 & 37 & 31 & \\
\hline 1 & 29 & 20 & 9 & \\
\hline Tumor size (cm) & & & & 0.001 \\
\hline$\leq 4 \times 3$ & 52 & 39 & 13 & \\
\hline$>4 \times 3$ & 45 & 18 & 27 & \\
\hline Location from anal verge & & & & 0.290 \\
\hline $0-5 \mathrm{~cm}$ & 52 & 28 & 24 & \\
\hline $5-10 \mathrm{~cm}$ & 45 & 29 & 16 & \\
\hline Local invasion & & & & 0.002 \\
\hline $\mathrm{T} 2$ & 26 & 22 & 4 & \\
\hline $\mathrm{T} 3+\mathrm{T} 4$ & 71 & 35 & 36 & \\
\hline Lymphatic invasion & & & & 0.005 \\
\hline N0 & 27 & 22 & 5 & \\
\hline $\mathrm{N} 1+\mathrm{N} 2$ & 70 & 35 & 35 & \\
\hline TNM stage & & & & 0.005 \\
\hline II & 27 & 22 & 5 & \\
\hline III & 70 & 35 & 35 & \\
\hline
\end{tabular}

The staging results were determined by two independent pathologists according to the 7th edition of the AJCC Cancer Staging system.

-PARP even after drug treatment (Figure 2C, 2D and Supplementary Figure 1B, 1C). These results suggested that NDRG1 could increase the sensitivity of CRC cells to oxaliplatin via promoting apoptosis.
Previous study reported that NDRG1 is necessary to P53-induced apoptosis. To further validate the effect of NDRG1, a selective knockdown of TP53 gene was performed in HCT116 cells (TP53KD), leading 
A

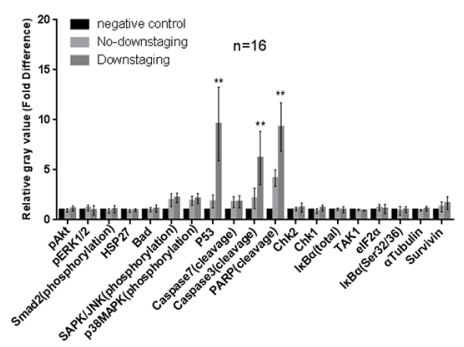

C

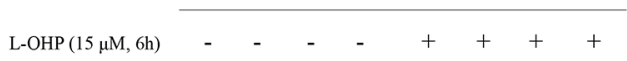

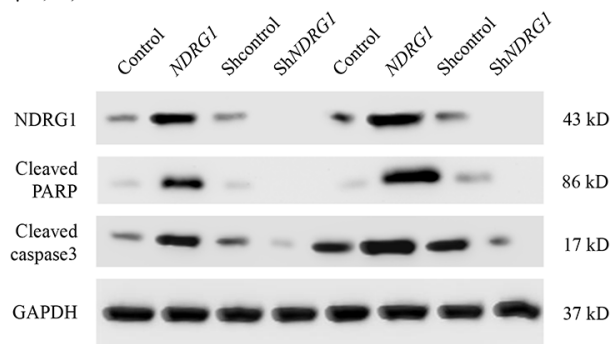

B

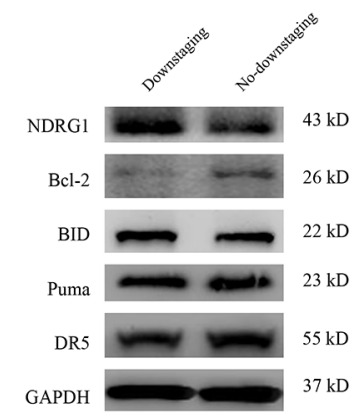

D

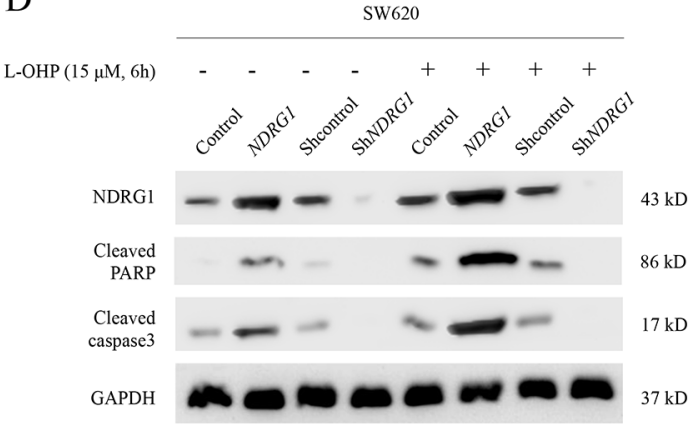

E

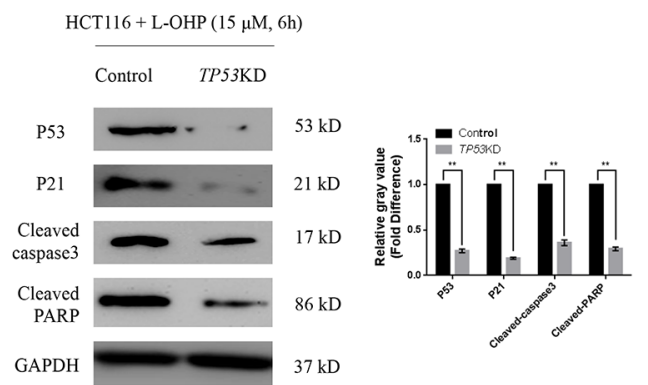

G

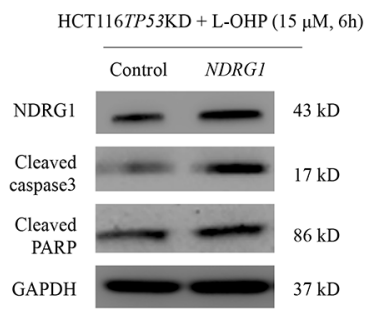

F

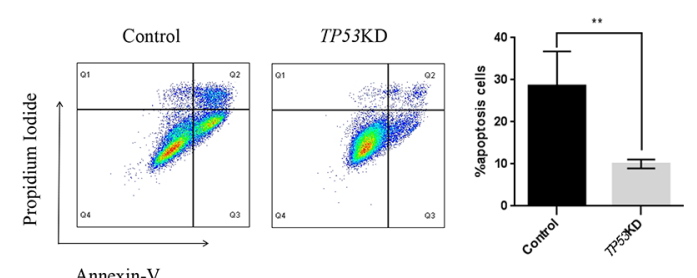

Annexin-V
H

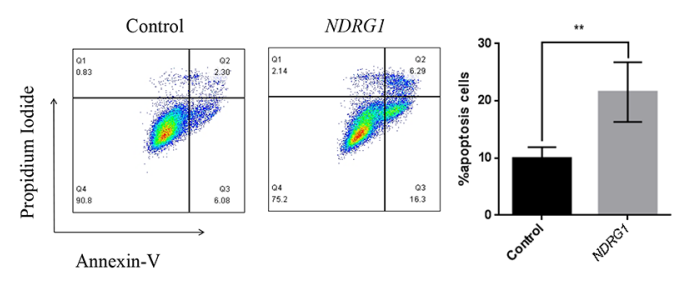

Figure 2: NDRG1 was necessary for oxaliplatin-triggered apoptosis. (A) Pathscan array showing elevated protein levels of P53, cleaved-caspase-3, and cleaved-PARP in samples from downstaging group. (B) Representative western blots of several main apoptosisregulating proteins, NDRG1 expression was increased while Bcl-2 was degraded in tissues from downstaging group. (C, D) Western blot assay showing protein levels of cleaved-PARP and -caspase-3 of HCT116 (C) and SW620 (D) cells and their NDRG1 derivates with or without oxaliplatin treatment. (E, F) TP53 knockdown attenuated oxaliplatin-triggered apoptosis. Apoptosis in HCT116TP53KD and control cells were measured with western blots (E) and confirmed by flow cytometry with Annexin V/PI (F). P21 was used as an evidence of successful knockdown of TP53. (G, H) NDRG1 expression rescued the drug resistance induced by TP53 knockdown. Apoptosis was measured with western blots $(\mathrm{G})$ and flow cytometry assay $(\mathrm{H})$. All histograms showed mean values from three independent experiments; bars indicated SD. *, $P<0.05, * *, P<0.01$. 
to attenuated response to oxaliplatin (Figure 2E, 2F). However, ectopic NDRG1 expression could restore the sensitivity of TP53KD cells to oxaliplatin (Figure 2G, 2H). The results in HT29 cells, a TP53 defective and oxaliplatin-resistant $\mathrm{CRC}$ cell line, were similar in the same experiment setting (Supplementary Figure 2A, $2 \mathrm{~B})$. Taken together, these data indicated that oxaliplatintriggered apoptosis depends on NDRG1 instead of TP53.

\section{NDRG1 induced the degradation of Bcl-2 via ubiquitin-proteasome pathway}

By blocking polymerization of Bax, Bcl-2 suppresses apoptosis and contributes to drug resistance in cancer cells. We first confirmed the counteractive role of Bcl-2 in oxaliplatin-triggered apoptosis in CRC cells. HCT116 cells were transfected with high amount of $\mathrm{Bcl}-2$ constructs $(10 \mu \mathrm{g})$, and apoptosis was dramatically attenuated (Supplementary Figure 2C). In addition, the over-expression of $\mathrm{Bcl}-2$ also suppressed the magnitude of apoptosis in HCT116NDRG1 cells (Supplementary Figure 2D), further validated our above-mentioned hypothesis that NDRG1 might promote apoptosis by targeting Bcl-2. Next, to explore the mechanisms for the loss of Bcl-2 protein, we treated
HCT116 and SW620 cells with cycloheximide (CHX), a translation inhibitor, before NDRG1 ectopic expression. However, Bcl-2 protein level still underwent a fast decline upon NDRG1 expression (Figure 3A), which indicated the loss of Bcl-2 was due to enhanced degradation instead of inhibition of protein synthesis. We then investigated if Bcl-2 degradation could be modulated by NDRG1. The pathway through which Bcl-2 degraded was investigated using both lysosome and proteasome pathway inhibitors. As shown, the lysosomal inhibitor BafilomycinA1 (BafA) had no effect on Bcl-2 degradation (Figure $3 \mathrm{~B}$ ) while the proteasomal inhibitor MG132 reversed the degradation of Bcl-2 in NDRG1 cells (Figure 3C, 3D). Moreover, proteins degraded by proteasome system are often first conjugated to multiple copies of ubiquitin through covalent binding. To verify the role of NDRG1 in Bcl-2 ubiquitination, immunoprecipitation assay was performed in NDRG1 over-expression and knockdown cell models. As shown, NDRG1 over-expressed cells displayed a much higher Bcl-2 ubiquitination level than control cells (Figure 4A, 4C) whereas shNDRG1 cells demonstrated the opposite (Figure 4B, 4D).

Bcl-2 contains 4 conserved homology domains (BH1-4), among which BH4 containing lysine residues
A



$\mathrm{C}$

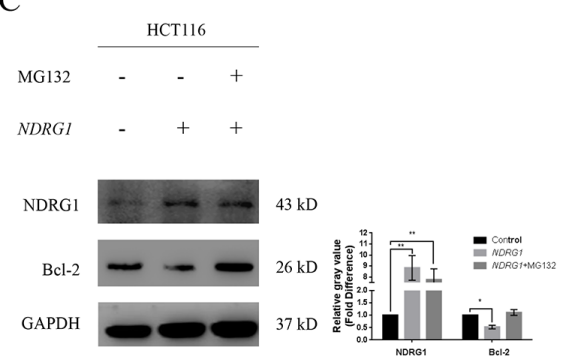

B

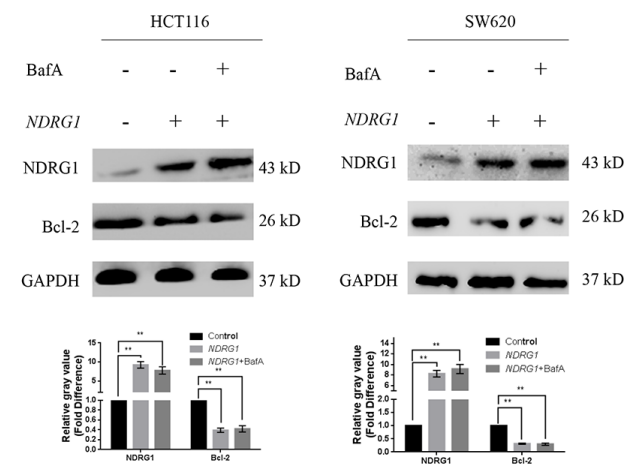

D

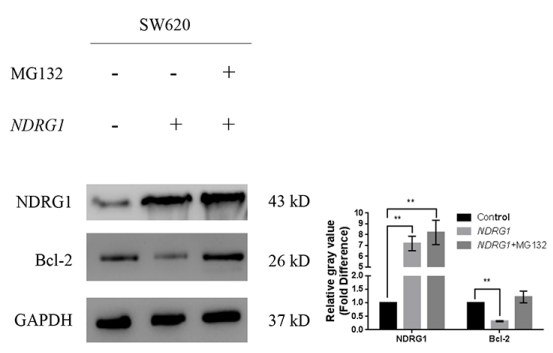

Figure 3: NDRG1 induced degradation of Bcl-2 via ubiquitin-proteasome pathway. (A) HCT116 and SW620 cells pretreated with with CHX $(20 \mu \mathrm{M}, 6 \mathrm{~h})$, a classical protein synthesis inhibitor, were transfected with NDRG1. Protein levels of Bcl-2 were analyzed with western blots 24 hours later. (B) After treated with lysosomal inhibitor BafilomycinA1 (BafA, $0.2 \mu \mathrm{M})$, protein levels of Bcl-2 were analyzed in control and NDRG1-transfected cells. (C, D) Western blots showing accumulation of Bcl-2 protein after treatment with MG132 $(10 \mu \mathrm{M})$ in $N D R G 1$-transfected cells. All histograms showed mean values from three independent experiments; bars indicated SD. * $P<$ $0.05, * *, P<0.01$. 
is very crucial to the process of ubiquitination. To further confirm our results, the $\mathrm{BH} 4$ deletion mutant of $\mathrm{Bcl}-2$ were constructed and introduced into HCT116 cells. As expected, the ubiquitination of Bcl-2 was significantly decreased in mutant cells even after NDRG1 over-expression (Figure 4E). These results suggested that NDRG1 induced the degradation of Bcl-2 via ubiquitin-proteasome pathway. The decrease of $\mathrm{Bcl}-2$ subsequently resulted in enhanced apoptosis.

\section{NDRG1 enhanced Bcl-2 ubiquitination by binding PKCa}

Previous studies demonstrated that Bcl-2 underwent ubiquitin-proteasome pathway after inhibition of protein kinase $\mathrm{C}(\mathrm{PKC})$, accompanied with induction of apoptosis [33]. According to the antagonism relationship between NDRG1 and PKC family in hematologic malignancy [26],

B

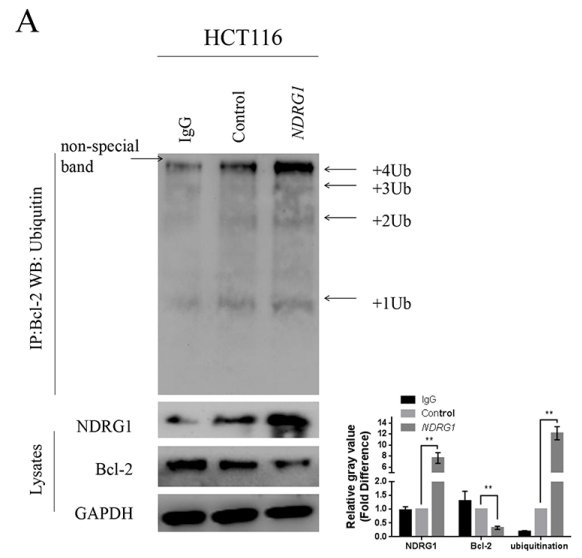

$\mathrm{C}$

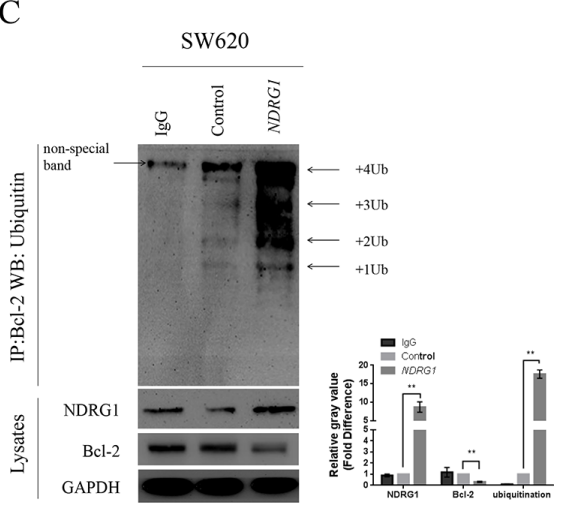

$\mathrm{D}$
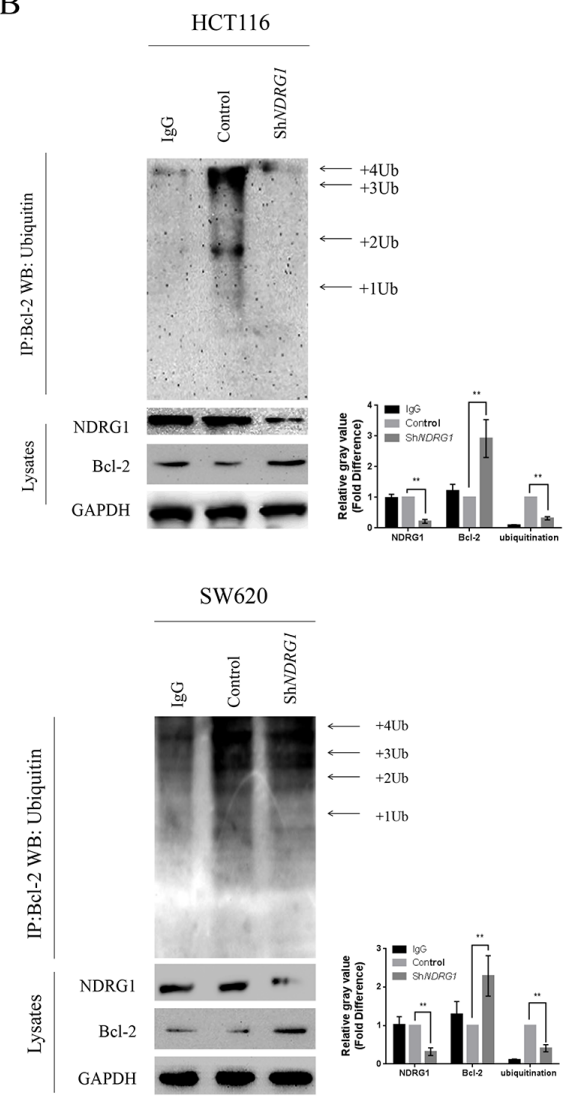

$\mathrm{E}$

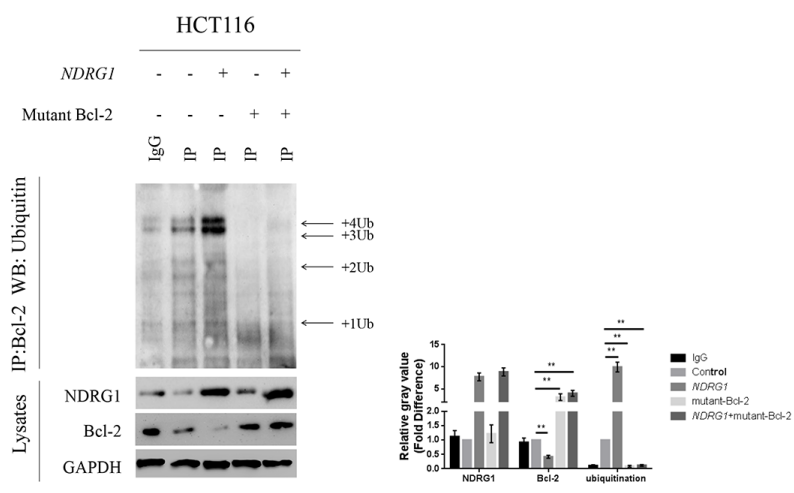

Figure 4: NDRG1 enhanced Bcl-2 ubiquitination. (A) Western blots with anti-ubiquitin antibody revealed Bcl-2 ubiquitination level in immunoprecipitates prepared from HCT116 cells over-expressing NDRG1 was much higher than control cells. The bands of the various ubiquitylated forms of Bcl-2 were as indicated. (B) Knockdown of NDRG1 suppressed Bcl-2 ubiquitinaiton. (C, D) Bcl-2 ubiquitination levels in SW620NDRG1 (C) or -shNDRG1 (D) cells. (E) the loss of BH4 domain impaired the ubiquitination of Bcl-2. HCT116NDRG1 cells were transfected with mutant (BH4 deletion) $\mathrm{Bcl}$-2. Immunoprecipitation assay was then performed to show different levels of ubiquitination. All histograms showed mean values from three independent experiments; bars indicated $\mathrm{SD} .{ }^{*}, P<0.05, * *, P<$ 0.01 . 
we assumed that similar mechanisms existed in CRC. To verify this hypothesis, we treated HCT116 and SW620 cells with GO6976 $(10 \mu \mathrm{M})$, a specific inhibitor of the
$\mathrm{PKC} \alpha$ and $\mathrm{PKC} \beta$. As expected, Bcl-2 degraded in a timedependent manner (Figure 5A). We then investigated the consequences of over-expression and depletion of $P K C \alpha$

A

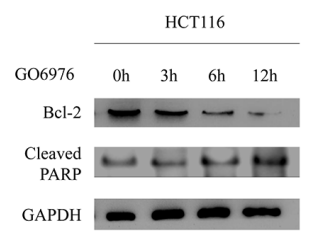

B

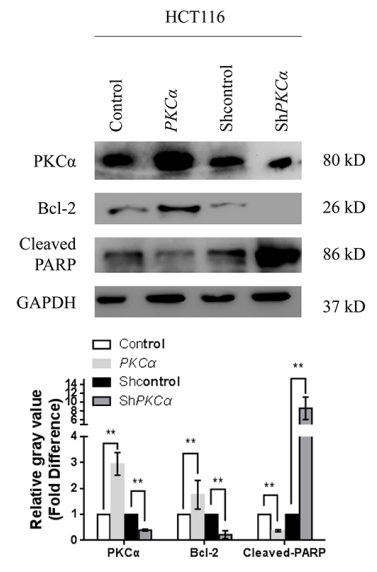

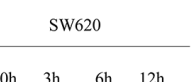
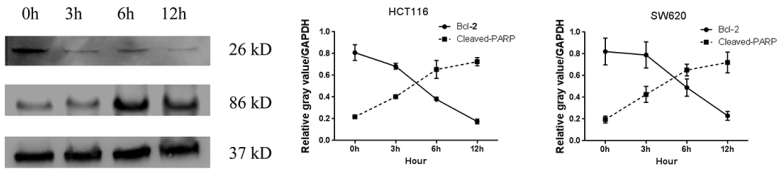

$\mathrm{C}$

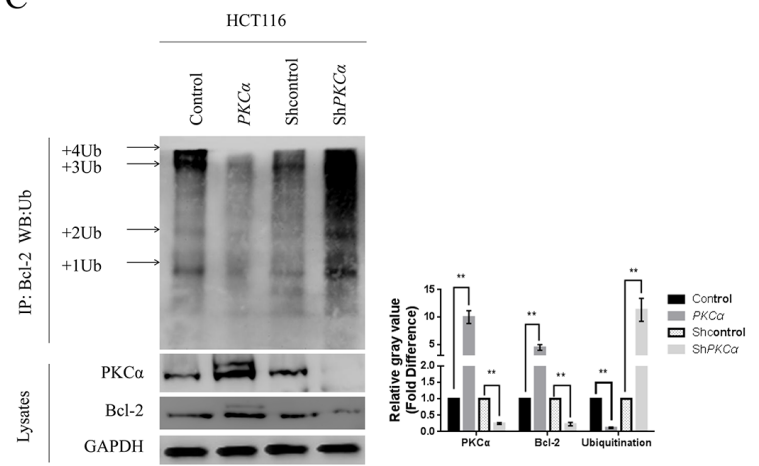

$\mathrm{D}$

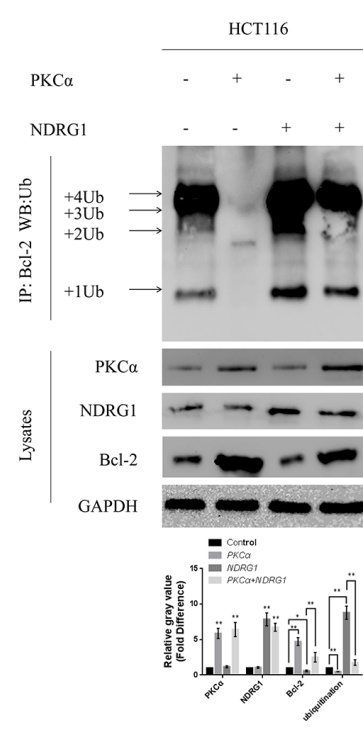

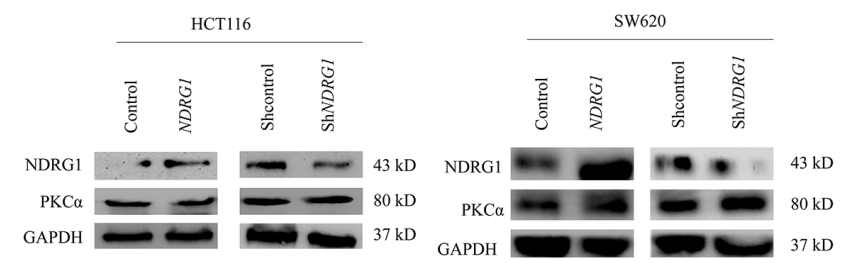

F

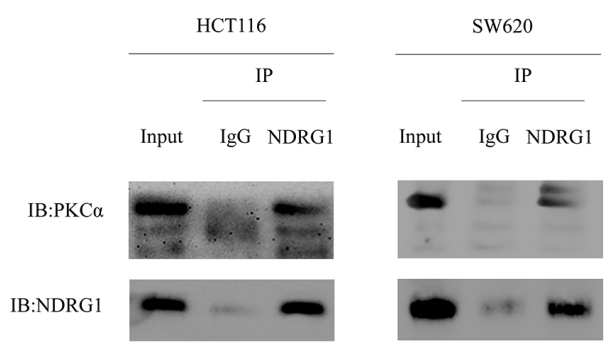

Figure 5: NDRG1 enhanced Bcl-2 ubiquitination via binding PKCa. (A) Bcl-2 was fast degraded with the treatment of GO6976, an inhibitor of PKC, accompanied with induction of apoptosis. Cleaved-PARP was a visualized evidence of cell apoptotic death. (B) HCT116 cells were transfected with pcDNA3.1/PKC $\alpha$ vector or $\mathrm{pLKO} / \mathrm{sh} P K C \alpha$ vector $(10 \mu \mathrm{g})$. Then protein levels of Bcl-2 and cleavedPARP were measured with western blots. (C) Western blots showing different Bcl-2 ubiquitination levels in HCT116 derivates with altered $P K C \alpha$ status. (D) NDRG1 reversed the suppression of Bcl-2 ubiquitination induced by $P K C \alpha$ over-expression. Immunoprecipation assay was performed as above described. (E) NDRG1 was unable to modulate protein level of PKC $\alpha$. Protein levels in different NDRG1 derivates of HCT116 cells were detected by western blots. (F) NDRG1 directly interacted with PKC $\alpha$ in CRC cell lines. All histograms showed mean values from three independent experiments; bars indicated SD. $*, P<0.05,{ }^{* *}, P<0.01$. 
and $P K C \beta$ respectively. As shown, over-expression of $P K C \alpha$ stabilized Bcl-2 and suppressed magnitude of apoptosis whereas depletion of $P K C \alpha$ resulted in the opposite (Figure 5B). However, neither over-expression nor knockdown of $P K C \beta$ affected Bcl-2 or apoptosis (Supplementary Figure 2E). Immunoprecipitation assay was also performed. As shown, Bcl-2 ubiquitination was suppressed after ectopic expression of $P K C \alpha$ whereas
A

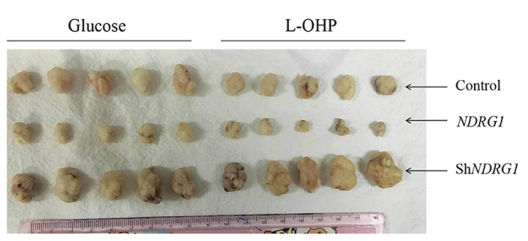

B

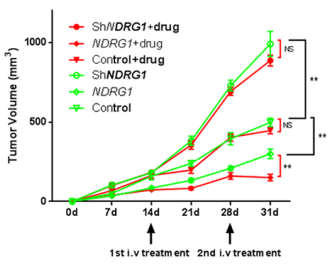

$\mathrm{C}$

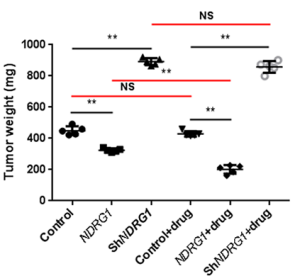

$\mathrm{D}$

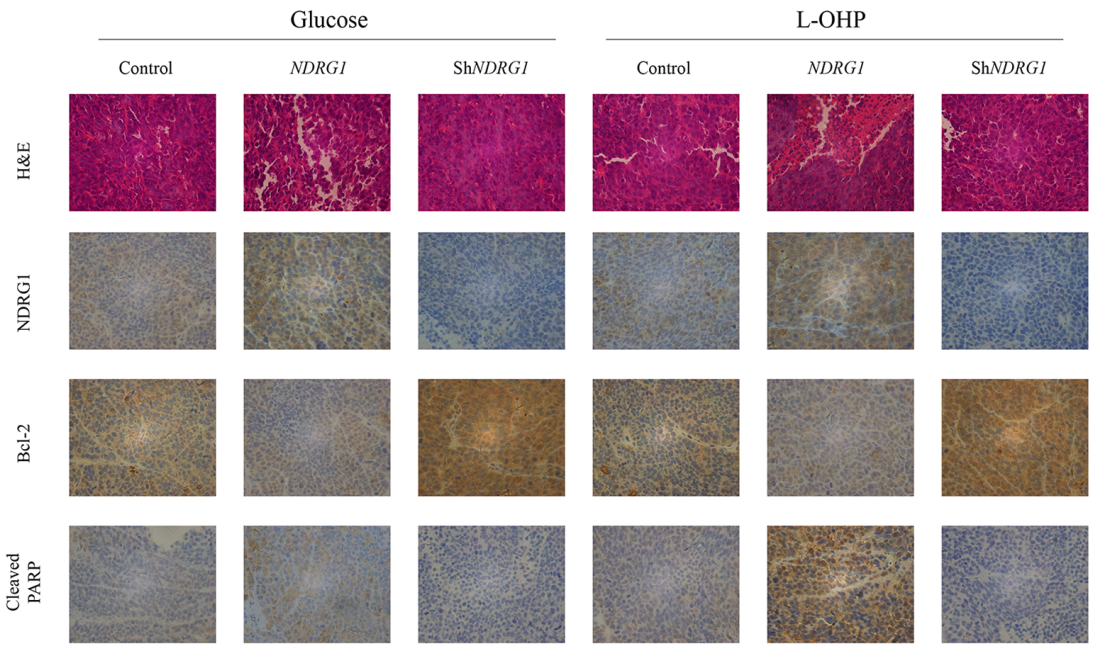

$\mathrm{E}$
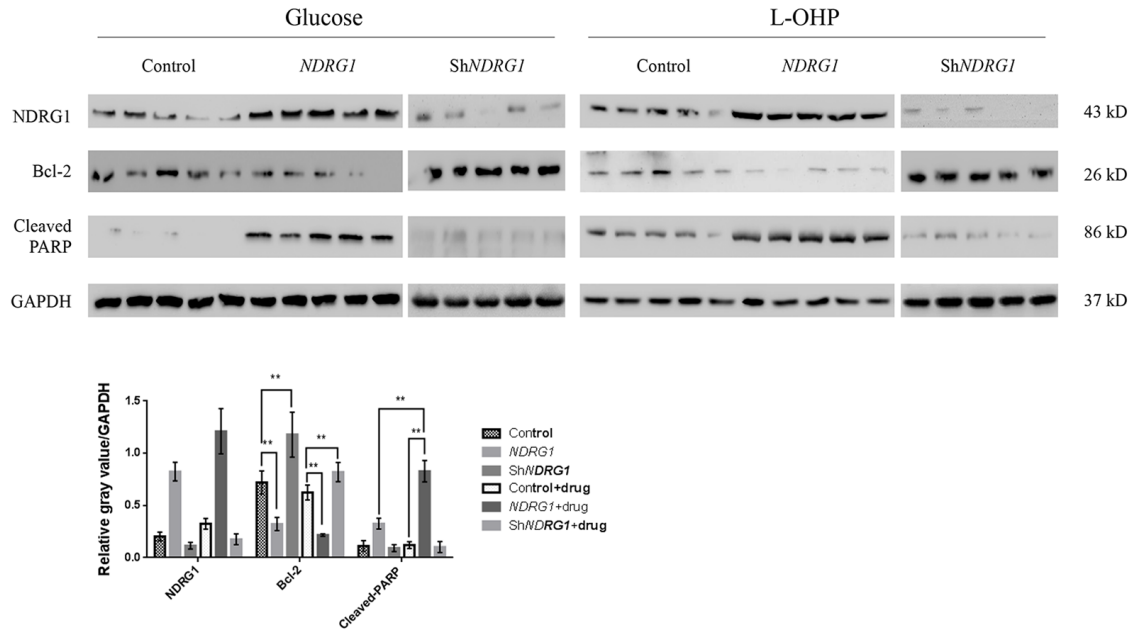

Figure 6: NDRG1 inhibited tumor growth and promoted apoptosis in vivo. (A) Representative image of xenografts formed by derivates of HCT116 CRC cells. The xenograft tumors were from control (glucose) or treated (L-OHP) group as indicated. (B, C) Quantitative analysis of tumor volume (B) and tumor weight (C). Arrows indicated two-time infusion of oxaliplatin from the tail vein. Red line indicated comparison between drug-treated and -untreated groups. (D) Immunohistochemical staining of NDRG1, Bcl-2, and cleaved-PARP in tumor xenografts with hematoxylin counterstaining. Magnification, $\times 200$. (E) Western blots showing protein levels of NDRG1, Bcl-2 and cleaved-PARP in xenograft tumor samples from HCT116-control, -NDRG1 and -shNDRG1 groups with or without drug treatment. Bars indicated SD. NS, not significant, ${ }^{*}, P<0.05, * *, P<0.01$. 
Table 3: Sequences for construction of plasmids

\begin{tabular}{|c|c|c|}
\hline Name & \multicolumn{2}{|c|}{ Oligonucleotides (5'-3') } \\
\hline & Forward primer & Reverse primer \\
\hline NDRG1 & GTGCAGAAGGGACTAGGCAG & GGGCACCCACGTAATAGACC \\
\hline Bcl-2 & CGTGATTGAAGACACCCCCT & CAGCCTGCAGCTTTGTTTCAT \\
\hline Bcl-2 mutant & $\begin{array}{l}\text { CGCTGGGAGAACAGGGTACTATAAGCTGT } \\
\text { CGCAGAG }\end{array}$ & $\begin{array}{l}\text { CTCTGCGACAGCTTATAGTACCCTGTTCTC } \\
\text { CCAGCG }\end{array}$ \\
\hline PKCa & GCGGAGGCAAGAGGTGG & AGGATTCACTTCCCACTGCG \\
\hline \multirow[t]{2}{*}{ PKC $\beta$} & CAGCTGGGCGAGTGACAG & CCAGGCTCAACGATGGAGTT \\
\hline & \multicolumn{2}{|c|}{ Hairpin sequences } \\
\hline Sh-NDRG1 & \multicolumn{2}{|c|}{ CCGGGCCTACATCCTAACTCGATTTCTCGAGAAATCGAGTTAGGATGTAGGCTTTTTG } \\
\hline Sh- PKCa & \multicolumn{2}{|c|}{ CCGGCCCGTCTTAACACCACCTGATCTCGAGATCAGGTGGTGTTAAGACGGGTTTTT } \\
\hline Sh- PKC $\beta$ & \multicolumn{2}{|c|}{ CCGGCCGGATGAAACTGACCGATTTCTCGAGAAATCGGTCAGTTTCATCCGGTTTTT } \\
\hline
\end{tabular}

depletion of $P K C \alpha$ led to enhanced ubiquitination (Figure 5C). Moreover, NDRG1 could reverse the suppression of Bcl-2 ubiquitination induced by PKC $\alpha$ (Figure 5D). Therefore, we speculated that NDRG1 might specially block the effect of PKC $\alpha$. Subsequently, western blots and RT-PCR were performed in HCT116 NDRG1 derivates to detect potential alterations of PKC $\alpha$. Unfortunately, no statistic differences were detected in either way (Figure 5E and Supplementary Figure 2F). Co-immunoprecipitation assay was finally performed to test potential direct interaction between NDRG1 and PKC $\alpha$. As shown, NDRG1 directly binded PKC $\alpha$ in HCT116 and SW620 cells (Figure 5F). These results indicated that NDRG1 might inhibit $\mathrm{PKC} \alpha$ function via direct binding. As consequences, ubiquitination of Bcl-2 was enhanced and CRC cells were more sensitive to apoptosis induced by oxaliplatin.

\section{NDRG1 inhibited tumor growth and promoted apoptosis in vivo}

Based on our in vitro findings, xenograft model was established to examine the in vivo effect of NDRG1 by injecting HCT116NDRG1 or -shNDRG1 cells into nude mice subcutaneously (Figure 6A). Oxaliplatin $(5 \mathrm{mg} / \mathrm{kg}$ in $5 \%$ glucose solution) was infused from the tail vein to simulate the neoadjuvant chemotherapy in human rectal cancer patients. After the infusion, the growth of NDRGI xenografts was significantly suppressed comparing with those from mice receiving glucose (Figure 6B, 6C). Moreover, xenograft tumors formed by control and shNDRG1 cells still underwent rapid growth even after drug treatment (Figure 6B, 6C). In addition, the levels of NDRG1 and Bcl-2 in xenografts were detected by IHC (Figure 6D and Supplementary Figure 2G) and western blots (Figure 6E). As shown, expression of $N D R G 1$ was always associated with decreased Bcl-2 and enhanced apoptosis. Accordingly, depletion of NDRG1 led to accumulation of Bcl-2 and impaired apoptosis. These data were consistent with our in vitro observations and suggested that the NDRG1 suppressed tumor growth and promoted apoptosis in vivo.

\section{DISCUSSION}

Even after recommended by guidelines, the necessity of including oxaliplatin into neoadjuvant chemotherapy has been controversial. Plenty of clinical trials concerning rectal cancer patients dominated by $\mathrm{T} 4$ and advanced T3 cases given sequential oxaliplatincontaining preoperative chemotherapy demonstrated high tumor response rates, prolonged overall survival, and acceptable toxicity $[4,5,7]$. Yet other researchers $[34,35]$ didn't observe similar promising results, suggesting that rectal cancer might be biologically heterogeneous with subgroups eligible for further individualization of therapy. Our investigation showed that NDRG1 was positively correlated with the downstaging rates and prognosis of LARC patients receiving neoadjuvant chemotherapy. Moreover, substantial apoptosis in cancer tissues from downstaging patients was detected by a pathscan array. These finding inspired us to focus on the role of NDRG1 in apoptosis.

Apoptosis is one of the major mechanisms of cell death in response to chemotherapy [36]. Alterations in susceptibility to apoptosis not only contribute to tumor development but also can grant resistance to anticancer therapies. In our study, elevated levels of P53, cleavedcaspase- 3 and cleaved-PARP were revealed by pathscan array. The P53 tumor suppressor protein can induce expression of numerous pro-apoptotic gene products which can activate intrinsic or extrinsic apoptotic pathways [37]. Current evidence points toward P53 functioning through transcriptional activation of pro- 
apoptotic target genes that contain TP53 gene binding sites within their regulatory regions [38]. Of the several genes to which P53 can directly target, NDRG1 has been considered to be necessary for P53-dependent apoptosis in several types of cancer including colorectal cancer [24]. NDRG1 is a potent metastasis suppressor in multiple tumor-types [39]. Plenty of studies manifest that overexpression of NDRG1 is able to inhibit the invasion and metastasis of CRC $[40,41]$. In contrast, some studies have demonstrated that NDRG1 promotes cell migration and invasion in certain type of carcinoma [42]. Hence, the role of $N D R G 1$ in the formation, development and treatment of cancers may depend on tissue-specific molecular profiles and remains to be clarified. We showed that NDRG1 increased sensitivity of CRC cells to oxaliplatin-triggered apoptosis. In line with this, knockdown of NDRG1 led to impaired response to chemotherapy. Moreover, in TP53 defective cancer cells, the ectopic NDRG1 expression could restore the response of CRC cells to oxaliplatin treatment. These results indicate that one of the major mechanisms by which P53 activate apoptotic pathway is targeting and activating NDRG1. Once NDRG1 is activated, it is sufficient to maintain the response of cancer cells to drug-induced apoptosis.

Dysregulation or blockade of apoptosis in cancer cells represents a potential mechanism of resistance to anticancer therapies $[43,44]$. Given the promoting activity of NDRG1 in apoptosis, we speculated that there might be interactions between NDRG1 and other apoptosis regulating proteins. As expected, the level of Bcl-2, a potent inhibitor of intrinsic apoptotic pathway [37], was decreased upon the expression of NDRG1. Overexpression of anti-apoptotic Bcl-2 family members in cancer has been associated with chemotherapy resistance in various human cancers, and preclinical studies have shown that agents targeting anti-apoptotic Bcl-2 family members have preclinical activity as single reagent and in combination with other anticancer drugs [45]. Thus, NDRG1 may exert its pro-apoptotic function through down-regulating Bcl-2. It was previously reported that the posttranscriptional modulation of Bcl-2, mainly through ubiquitination and phosphorylation, was responsible for its stability $[46,47]$. Bcl-2 was shown ubiquitinated and rapidly degraded in apoptosis trigged by TNF- $\alpha$ [48] and UV exposure [49]. Furthermore, attenuation of this ubiquitination process contributed to chemo-resistance in cancer cells. Therefore, the process of regulating Bcl2 stability seems to be crucial in sensitizing cancer cells to chemotherapeutics. In our subsequent investigation, we focused on the cellular degradative machinery for Bcl-2. Lysosomal and proteasomal pathways were both explored. We found that MG132, a proteasome inhibitor, led to accumulation of $\mathrm{Bcl}-2$ protein in NDRG1-transfected cells, which suggested the degradation of Bcl-2 induced by NDRG1 was blocked. Thus, Bcl-2 degraded through proteasome pathway. Moreover, immunoprecipitation assay provided solid evidence that NDRG1 enhanced Bcl2 ubiquitination and subsequent proteasomal degradation. In the absence of $\mathrm{Bcl}-2, \mathrm{CRC}$ cells were more sensitive to oxaliplatin-triggered apoptosis.

It has been reported that that PKC or Erk1/2 prolonged half life of $\mathrm{Bcl}-2$ via phosphorylation of several sites in Bcl-2 protein [50]. Among several isoforms, $\mathrm{PKC} \alpha$ was proved to suppress Bcl-2 ubiquitination and increased its stability. We then investigated several potential mechanisms and finally discovered that NDRG1 might suppress PKC $\alpha$ function via direct binding. Through this, NDRG1 could enhance Bcl-2 ubiquitination and promote apoptosis. However, the detailed molecular mechanisms through which NDRG1 affects PKC $\alpha$ remains to be clarified in further studies.

The present study highlights the pivotal role of NDRG1 in regulating apoptosis of CRC. In summary, through interacting with PKC $\alpha$, NDRG1 enhances the degradation of $\mathrm{Bcl}-2$ and promotes apoptosis in CRC. In the presence of NDRG1, oxaliplatin-based chemotherapy can yield great killing activity, resulting in higher downstaging rates and better prognosis of LARC patients. As far as we are concerned, our study is the first demonstration that rectal cancer can be stratified by NDRG1 status in terms of the response to chemotherapy. These findings provide a novel predictive biomarker for the treatment of CRC. However, this conclusion needs to be confirmed in further clinical trial.

\section{MATERIALS AND METHODS}

\section{Ethics statement}

Investigation has been conducted in accordance with the ethical standards and according to the Declaration of Helsinki and according to national and international guidelines and has been approved by the Medical Ethics Committee of Ruijin Hospital. Informed consent for medical research and publication has been obtained from all patients.

\section{Patients and treatment strategy}

This study was performed to evaluate the clinical outcome of patients with locally advanced rectal cancer treated with neoadjuvant chemotherapy. Patients enrollment criteria were as follows: age between 18 and 70 years; primary rectal cancer; histological diagnosis of adenocarcinoma; TNM stage $\geq \mathrm{T} 3$ or positive regional lymph nodes revealed by endoscopic ultrasonography or magnetic resonance images (MRI); distance to anal verge $\leq 10 \mathrm{~cm}$; Eastern Cooperative Oncology Group (ECOG) performance status score $\leq 2$; no history of previous chemotherapy. All the patients were given a clinical stage either by endoscopic ultrasonography (EUS) or magnetic resonance imaging (MRI) prior to treatment. 
Oxaliplatin-based chemotherapy was then delivered to all the patients for two cycles before surgery. Patients receiving FOLFOX regimen (oxaliplatin $85 \mathrm{mg} / \mathrm{m}^{2}$ on day 1 , leucovorin $200 \mathrm{mg} / \mathrm{m}^{2}$ on day $1,5-\mathrm{Fu} 400 \mathrm{mg} /$ $\mathrm{m}^{2}$ intravenous infusion on day 1 , then $600 \mathrm{mg} / \mathrm{m}^{2} /$ day continuous infusion for 2 days) or XELOX regimen (oxaliplatin $100 \mathrm{mg} / \mathrm{m}^{2}$ on day 1 , capecitabine 1,000 $\mathrm{mg} / \mathrm{m}^{2}$ bid on days 1-14) were all included. Surgery was scheduled within 6-8 weeks after the completion of chemotherapy, and standard TME was then performed. For each patient, the resected specimen was examined by two independent pathologists for pathological staging. The pathological stage was compared with the pre-chemotherapy stage. Complete regression (CR) was defined as no cancer cells in the rectal wall or mesorectum (ypT0N0). Downstaging was defined as achieving some tumorous and lymphatic regression including CR. Nodownstaging was defined as no difference between prechemotherapy stage and final pathological stage or TNM stage upgrading during preoperative chemotherapy. All patients were routinely followed. Sixteen samples were selected by simple randomization conducted with SAS software. Protein and RNA for further research were obtained from specimen of preoperative colonoscopy biopsy and surgical resection.

\section{Reagents and anitbodies}

The Pathscan Sampler Kit (\#7851) and Apoptosis Antibody Sampler Kit (\#9930) including anti-cleaved PARP, anti-cleaved caspase-3, anti-cleaved caspase-8, and anti-cleaved caspase- 9 antibodies were purchased from Cell Signaling Technology (Beverly, MA, USA). The In Situ Cell Death Detection Kit (11684795910) was obtained from Roche (Indianapolis, IN, USA). Anti-P53 (\#2524), anti-Bcl-2 (\#15071) antibodies were also obtained from Cell Signaling Technology. Anti-NDRG1 antibody (WH0010397M3) was from Sigma Aldrich (St. Louis, MO, USA). Anti-PKC $\alpha$ (\#2056) antibody was obtained from Cell Signaling Technology. AntiPKC $\beta$ (2099) antibody was obtained from Santa Cruz Biotechnology (Santa Cruz, CA, USA). Oxaliplatin (3422) was provided by Sanofi (Paris, France). The PKC inhibitor GO6976 (S7119) was obtained from Selleck (Houston, TX, USA).

\section{Pathscan array}

Conducting of pathscan array was strictly followed the manufacturer's protocol. In brief, the glass slides containing detecting antibody matrix was prepared and assembled. Then the blocking buffer was added in each well and incubated in room temperature for 15 minutes. After washing, a total protein of $30 \mu \mathrm{g}$ was added in each well and incubated at $4{ }^{\circ} \mathrm{C}$ overnight on an orbital shaker. Then the slide was washed with PBS and placed on a plastic dish. The images were captured using an Oddessy fluorescent imaging system (LI-COR Biotechnology, Lincoln, NE, USA).

\section{Cell culture and transfections}

Human colorectal cancer cells HCT116, SW620 and HT29 were from American Type Culture Collection (ATCC). Standard growth media for HCT116 and HT29 was McCoy's 5A (Invitrogen, Carlsbad, CA, USA) supplemented with $10 \%$ fetal bovine serum (FBS, HyClone, Logan, UT, USA). SW620 was cultured in Leibovitz's L-15 medium (Gibco) with 10\% FBS. All cells were maintained in a $37^{\circ} \mathrm{C}$ incubator with $5 \% \mathrm{CO}_{2}$. For transient transfection, cells were transfected with pcDNA3.1 (over-expression) or pLKO (knockdown) plasmids encoding target sequences. For establishment of stable cell Lines, the stable clones were selected by puromycin $(5 \mu \mathrm{g} / \mathrm{mL})$ for 2 weeks. Sequences or hairpin sequences used for construction were listed in Table 3. All constructs were confirmed by sequencing.

The staging results were determined by two independent pathologists according to the 7th edition of the AJCC Cancer Staging system.

\section{Western blot and immunoprecipitation}

For western blot analysis, cells were lysed in RIPA buffer (50 mM Tris- $\mathrm{HCl}, \mathrm{pH} 6.8,8 \mathrm{M}$ urea, 5\% $\beta$-mercaptoethanol, $2 \% \mathrm{SDS}$, and $1 \times$ protease inhibitor mixture). The total cell lysates was sonicated and then centrifuged at $14,000 \mathrm{~g}$ for $5 \mathrm{~min}$ at $4{ }^{\circ} \mathrm{C}$ to remove cell debris. The supernates were then separated in $12.5 \%$ SDS-PAGE. Protein levels were revealed by enhanced chemiluminescence (ECL) method. For Bcl2 immunoprecipitation assay, protein extracts prepared in lysis buffer (1\% CHAPSO, $30 \mathrm{mM}$ Tris-HCl, $\mathrm{pH} 8.0$, $150 \mathrm{mM} \mathrm{NaCl}, 5 \mathrm{mM}$ EDTA, and $1 \times$ protease inhibitor mixture) were firstly pre-cleared to reduce non-specific binding of proteins to sepharose beads. The supernatants was incubated with Bcl-2 antibody overnight and then with protein $\mathrm{A} / \mathrm{G}$ agarose for 4 hours at $4{ }^{\circ} \mathrm{C}$. After washing five times with cold PBS, the immunoprecipitates was boiled and subjected to western blot analysis with antiubiquitin antibody. For detecting NDRG1/PKC binding, $5 \times 10^{6}$ cells were harvested with immunoprecipitation lysis buffer (20 mM Tris- $\mathrm{HCl}, \mathrm{pH} 7.6 ; 150 \mathrm{mM} \mathrm{NaCl}$; $1 \mathrm{mM}$ EDTA; 0.5\% NP-40; 10\% glycerol; $1 \mathrm{mM}$ PMSF; protease inhibitor cocktail). After sonication, the lysates were centrifuged $(14,000 \mathrm{~g}, 15 \mathrm{~min})$ at $4^{\circ} \mathrm{C}$. Immunoprecipitation was performed using anti-NDRG1 antibody. After adding protein $\mathrm{A} / \mathrm{G}$ agarose, equal amounts of lysates were incubated with NDRG1 antibody or IgG for $16 \mathrm{~h}$. Subsequently, immunoprecipitates were washed 3 times with RIPA buffer. All incubations and washes 
were performed at $4^{\circ} \mathrm{C}$ with gentle rotation. Proteins were eluted from beads for western blots.

\section{Reverse transcription-polymerase chain reaction (RT-PCR)}

RT-PCR was performed as we described previously [41]. The involving primers were as follows: NDRG1 forward: 5'-CTCCTGCAAGAGTTTGATGTCC-3' and reverse: 5'-TCATGCCGATGTCATGGTAGG-3'. PKC $\alpha$ forward: 5'-GTCCACAAGAGGTGCCATGAA-3' and reverse: 5'-AAGGTGGGGCTTCCGTAAGT-3'.

\section{Flow cytometry analysis}

For flow cytometry analysis, both floating and attached cells were collected, after washing twice with ice-cold PBS, cells were resuspended in $400 \mu$ binding buffer (10 mM HEPES, $140 \mathrm{mM} \mathrm{NaCl}$, and $2.5 \mathrm{mM}$ $\mathrm{CaCl}_{2}, \mathrm{pH}$ 7.4) and stained with annexin $\mathrm{V}$-enhanced green fluorescent protein/propidium iodide (PI), using an annexin $\mathrm{V}$-enhanced green fluorescent protein apoptosis detection kit (BD science, UK). After incubation for 15 minutes, the cells were collected and analyzed in a FACScanflow cytometry analyzer (Beckman, Brea, CA, USA) following the manufacturer's protocol. Both PI- and annexin V-negative cells (quadrant 4) were intact cells, PInegative and annexin $\mathrm{V}$-positive cells were considered as early apoptotic (quadrant 3) cells, both PI- and annexin V-positive (quadrant 2) cells were late apoptotic cells, PI-positive and annexin V-negative cells were considered to be mechanically injured (quadrant 1) during the experiment.

\section{In vivo studies}

Mice were maintained at the animal experiment center of Ruijin Hospital under standard conditions following institutional guidelines. All procedures were approved by the Institute Ethical Committee for animal use. A total of $10 \times 10^{6} \mathrm{HCT} 116 N D R G 1$ or HCT116shNDRG1 cells along with control cells were injected subcutaneously into nude mice (male BALB/c nu/nu nude mice, 4 -week-old, 5 per group). To assess the effect of oxaliplatin on different NDRG1 derivates in vivo, mice were divided into two groups receiving oxaliplatin treatment or glucose as a control. Treatments were started from day 14. The treatment schedule consisted of 2 intravenous infusions, every 2 weeks, $5 \mathrm{mg} / \mathrm{kg}$ injection of oxaliplatin from tail vein each time. The drug dose was decided on the basis of literature data and results of our preliminary experiment showing that this dose was generally well tolerated whereas higher dosages were associated with death of mice. Tumor size was measured every 7 days using calipers and tumor volume (V) was determined by measuring the length and width of the tumor and using the formula $\mathrm{V}=\left(\right.$ width $^{2} \times$ length $) / 2$.

\section{Immunohistochemical staining}

Immunohistochemical (IHC) staining was performed on paraffin-embedded tissue sections. The tissue sections were deparaffinized, rehydrated, and microwaved-heated in sodium citrate buffer $(10 \mathrm{mmol} / \mathrm{L}, \mathrm{pH} 6.0)$ for antigen retrieval. Then, the slides were incubated with primary antibody (anti-NDRG1, anti-Bcl-2, or anti-cleaved PARP). Counterstaining was performed using hematoxylin. The scoring was carried out by two independent pathologists blinded to the clinical characteristics of the patients according to proportion of cell staining $(0=0 \%, 1=$ $\leq 25 \%, 2=26 \%$ to $50 \%, 3=51 \%$ to $75 \%, 4=>75 \%$ positive cells $)$ and the staining intensity ( $0=$ no staining, 1 = weak, 2 = moderate, $3=$ strong). Scores of cell staining and staining intensity were multiplied. An overall score of $\leq 7$ was defined as negative, while a score $>7$ was defined as positive.

\section{Statistics}

SPSS software (version 19.0) was utilized for statistical analysis. Differences between continuous variables (protein levels and RNA levels) were compared using unpaired $t$ test. Relationship between NDRG1 expression and clinicopathologic variables were measured by Pearson Chi-square $(\chi 2)$ test. $R$ values were determined by Spearman correlation analysis. Overall survival was assessed by Kaplan-Meier method, and difference between survival curves was determined by using the log-rank test. Growing curves of xenograft tumors from different NDRG1 derivates were compared with two-way analysis of variance (ANOVA) method. Differences with a $P$ value $<0.05$ were considered as statistically significant.

\section{Abbreviations}

CRC, colorectal cancer; NDRG1, N-myc downstream regulated gene-1; RT-PCR, reverse transcription-polymerase chain reaction; CRT, chemoradiation therapy; TME, total mesorectal excision; LARC, locally advanced rectal cancer.

\section{Author contributions}

Conception and design: Xiao Yang, Jing Sun, Yanfeng Lv, Minhua Zheng. Development of methodology: Xiao Yang, Fan Zhu, Chaoran Yu, Jing Sun. Acquisition of data: Fan Zhu, Xiao Yang, Yanfeng Lv, Jing Sun, Minhua Zheng. Analysis and interpretation of data: Xiao Yang, Jiaoyang Lu, Luyang Zhang. Writing, review, and revision of the manuscript: Xiao Yang, Jing Sun, Fan Zhu, Minhua Zheng. Administrative, technical, or material support: Xiao Yang, Fan Zhu, Jiaoyang Lu. Study supervision: Yanfeng Lv, Jing Sun, Minhua Zheng 


\section{ACKNOWLEDGMENTS}

The study is financially supported by National Natural Science Foundation of China (NSFC) (81402423, 81572818), Science and Technology Commission of Shanghai Municipality (14YF1402800).

\section{CONFLICTS OF INTEREST}

The authors declare no conflicts of interest.

\section{REFERENCES}

1. Bosset JF, Calais G, Mineur L, Maingon P, StojanovicRundic S, Bensadoun RJ, Bardet E, Beny A, Ollier JC, Bolla M, Marchal D, Van Laethem JL, Klein V, et al. Fluorouracil-based adjuvant chemotherapy after preoperative chemoradiotherapy in rectal cancer: long-term results of the EORTC 22921 randomised study. Lancet Oncol. 2014; 15:184-190.

2. Pucciarelli S, Gagliardi G, Maretto I, Lonardi S, Friso ML, Urso E, Toppan P, Nitti D. Long-term oncologic results and complications after preoperative chemoradiotherapy for rectal cancer: a single-institution experience after a median follow-up of 95 months. Ann Surg Oncol. 2009; 16:893-899.

3. Sauer R, Becker H, Hohenberger W, Rodel C, Wittekind C, Fietkau R, Martus P, Tschmelitsch J, Hager E, Hess CF, Karstens JH, Liersch T, Schmidberger H, et al. Preoperative versus postoperative chemoradiotherapy for rectal cancer. N Engl J Med. 2004; 351:1731-1740.

4. Dueland S, Ree AH, Groholt KK, Saelen MG, Folkvord S, Hole KH, Seierstad T, Larsen SG, Giercksky KE, Wiig JN, Boye K, Flatmark K. Oxaliplatin-containing preoperative therapy in locally advanced rectal cancer: local response, toxicity and long-term outcome. Clin Oncol (R Coll Radiol). 2016; 28:532-539.

5. Lu JY, Xiao Y, Qiu HZ, Wu B, Lin GL, Xu L, Zhang GN, $\mathrm{Hu}$ K. Clinical outcome of neoadjuvant chemoradiation therapy with oxaliplatin and capecitabine or 5-fluorouracil for locally advanced rectal cancer. J Surg Oncol. 2013; 108:213-219.

6. O'Brien SM, Cunningham CC, Golenkov AK, Turkina AG, Novick SC, Rai KR. Phase I to II multicenter study of oblimersen sodium, a Bcl-2 antisense oligonucleotide, in patients with advanced chronic lymphocytic leukemia. J Clin Oncol. 2005; 23:7697-7702.

7. Rodel C, Graeven U, Fietkau R, Hohenberger W, Hothorn T, Arnold D, Hofheinz RD, Ghadimi M, Wolff HA, LangWelzenbach M, Raab HR, Wittekind C, Strobel P, et al. Oxaliplatin added to fluorouracil-based preoperative chemoradiotherapy and postoperative chemotherapy of locally advanced rectal cancer (the German CAO/ARO/ AIO-04 study): final results of the multicentre, open-label, randomised, phase 3 trial. Lancet Oncol. 2015; 16:979-989.
8. Santoro V, Jia R, Thompson H, Nijhuis A, Jeffery R, Kiakos K, Silver AR, Hartley JA, Hochhauser D. Role of reactive oxygen species in the abrogation of oxaliplatin activity by cetuximab in colorectal cancer. J Natl Cancer Inst. 2016; 108:djv394.

9. Tummala S, Gowthamarajan K, Satish Kumar MN, Wadhwani A. Oxaliplatin immuno hybrid nanoparticles for active targeting: an approach for enhanced apoptotic activity and drug delivery to colorectal tumors. Drug Deliv. 2016; 23:1773-1787.

10. Cory S, Adams JM. Killing cancer cells by flipping the Bcl-2/Bax switch. Cancer Cell. 2005; 8:5-6.

11. Green DR, Reed JC. Mitochondria and apoptosis. Science. 1998; 281:1309-1312.

12. Carson R, Celtikci B, Fenning C, Javadi A, Crawford N, Perez-Carbonell L, Lawler M, Longley DB, Johnston PG, Van Schaeybroeck S. HDAC inhibition overcomes acute resistance to MEK inhibition in BRAF-mutant colorectal cancer by downregulation of c-FLIPL. Clin Cancer Res. 2015; 21:3230-3240.

13. von Karstedt S, Conti A, Nobis M, Montinaro A, Hartwig T, Lemke J, Legler K, Annewanter F, Campbell AD, Taraborrelli L, Grosse-Wilde A, Coy JF, El-Bahrawy MA, et al. Cancer cellautonomous TRAIL-R signaling promotes KRAS-driven cancer progression, invasion, and metastasis. Cancer Cell. 2015; 27:561-573.

14. Kang $\mathrm{MH}$, Reynolds CP. Bcl-2 inhibitors: targeting mitochondrial apoptotic pathways in cancer therapy. Clin Cancer Res. 2009; 15:1126-1132.

15. Niu X, Zhao J, Ma J, Xie C, Edwards H, Wang G, Caldwell JT, Xiang S, Zhang X, Chu R, Wang ZJ, Lin H, Taub JW, Ge Y. Binding of released Bim to Mcl-1 is a mechanism of intrinsic resistance to ABT-199 which can be overcome by combination with daunorubicin or cytarabine in AML cells. Clin Cancer Res. 2016; 22:4440-4451.

16. Kovacevic Z, Menezes SV, Sahni S, Kalinowski DS, Bae DH, Lane DJ, Richardson DR. The metastasis suppressor, N-MYC downstream-regulated gene-1 (NDRG1), down-regulates the ErbB family of receptors to inhibit downstream oncogenic signaling pathways. J Biol Chem. 2016; 291:1029-1052.

17. Strzelczyk B, Szulc A, Rzepko R, Kitowska A, Skokowski J, Szutowicz A, Pawelczyk T. Identification of high-risk stage II colorectal tumors by combined analysis of the NDRG1 gene expression and the depth of tumor invasion. Ann Surg Oncol. 2009; 16:1287-1294.

18. Li EY, Huang WY, Chang YC, Tsai MH, Chuang EY, Kuok QY, Bai ST, Chao LY, Sher YP, Lai LC. Aryl hydrocarbon receptor activates NDRG1 transcription under hypoxia in breast cancer cells. Sci Rep. 2016; 6:20808.

19. Luo EC, Chang YC, Sher YP, Huang WY, Chuang LL, Chiu YC, Tsai MH, Chuang EY, Lai LC. MicroRNA-769-3p down-regulates NDRG1 and enhances apoptosis in MCF-7 cells during reoxygenation. Sci Rep. 2014; 4:5908. 
20. Li Y, Pan P, Qiao P, Liu R. Downregulation of N-myc downstream regulated gene 1 caused by the methylation of CpG islands of NDRG1 promoter promotes proliferation and invasion of prostate cancer cells. Int J Oncol. 2015; 47:1001-1008.

21. Wissing MD, Mendonca J, Kim E, Kim E, Shim JS, Kaelber NS, Kant H, Hammers H, Commes T, Van Diest PJ, Liu JO, Kachhap SK. Identification of cetrimonium bromide and irinotecan as compounds with synthetic lethality against NDRG1 deficient prostate cancer cells. Cancer Biol Ther. 2013; 14:401-410.

22. Chen S, Han YH, Zheng Y, Zhao M, Yan H, Zhao Q, Chen GQ, Li D. NDRG1 contributes to retinoic acidinduced differentiation of leukemic cells. Leuk Res. 2009; 33:1108-1113.

23. Oh YM, Park HB, Shin JH, Lee JE, Park HY, Kho DH, Lee JS, Choi H, Okuda T, Kokame K, Miyata T, Kim IH, Lee $\mathrm{SH}$, et al. Ndrg1 is a T-cell clonal anergy factor negatively regulated by $\mathrm{CD} 28$ costimulation and interleukin-2. Nat Commun. 2015; 6:8698.

24. Stein S, Thomas EK, Herzog B, Westfall MD, Rocheleau JV, Jackson RS 2nd, Wang M, Liang P. NDRG1 is necessary for p53-dependent apoptosis. J Biol Chem. 2004; 279:48930-48940.

25. Zhang D, Jia J, Zhao G, Yue M, Yang H, Wang J. NDRG1 promotes the multidrug resistance of neuroblastoma cells with upregulated expression of drug resistant proteins. Biomed Pharmacother. 2015; 76:46-51.

26. Zheng Y, Wang LS, Xia L, Han YH, Liao SH, Wang XL, Cheng JK, Chen GQ. NDRG1 is down-regulated in the early apoptotic event induced by camptothecin analogs: the potential role in proteolytic activation of PKC delta and apoptosis. Proteomics. 2009; 9:2064-2075.

27. Jin R, Liu W, Menezes S, Yue F, Zheng M, Kovacevic Z, Richardson DR. The metastasis suppressor NDRG1 modulates the phosphorylation and nuclear translocation of $\beta$-catenin through mechanisms involving FRAT1 and PAK4. J Cell Sci. 2014; 127:3116-3130.

28. Liu W, Xing F, Iiizumi-Gairani M, Okuda H, Watabe M, Pai SK, Pandey PR, Hirota S, Kobayashi A, Mo YY, Fukuda K, Li Y, Watabe K. N-myc downstream regulated gene 1 modulates Wnt- $\beta$-catenin signalling and pleiotropically suppresses metastasis. EMBO Mol Med. 2012; 4:93-108.

29. Wei MA, Meng NA, Tang $C$, Wang $H$, Lin $Z$. Overexpression of $\mathrm{N}$-myc downstream-regulated gene 1 inhibits human glioma proliferation and invasion via phosphoinositide 3-kinase/AKT pathways. Mol Med Rep. 2015; 12:1050-1058

30. Kovacevic Z, Chikhani S, Lui GY, Sivagurunathan S, Richardson DR. The iron-regulated metastasis suppressor NDRG1 targets NEDD4L, PTEN, and SMAD4 and inhibits the PI3K and Ras signaling pathways. Antioxid Redox Signal. 2013; 18:874-887.

31. Dixon KM, Lui GY, Kovacevic Z, Zhang D, Yao M, Chen Z, Dong Q, Assinder SJ, Richardson DR. Dp44mT targets the AKT, TGF- $\beta$ and ERK pathways via the metastasis suppressor NDRG1 in normal prostate epithelial cells and prostate cancer cells. Br J Cancer. 2013; 108:409-419.

32. Mao Z, Sun J, Feng B, Ma J, Zang L, Dong F, Zhang D, Zheng $\mathrm{M}$. The metastasis suppressor, N-myc downregulated gene 1 (NDRG1), is a prognostic biomarker for human colorectal cancer. PLoS One. 2013; 8:e68206.

33. Peng B, Ganapathy S, Shen L, Huang J, Yi B, Zhou X, Dai W, Chen C. Targeting Bcl-2 stability to sensitize cells harboring oncogenic ras. Oncotarget. 2015; 6:22328-22337. doi: 10.18632/oncotarget.4084.

34. Gerard JP, Azria D, Gourgou-Bourgade S, Martel-Lafay I, Hennequin C, Etienne PL, Vendrely V, Francois E, de La Roche G, Bouche O, Mirabel X, Denis B, Mineur L, et al. Clinical outcome of the ACCORD 12/0405 PRODIGE 2 randomized trial in rectal cancer. J Clin Oncol. 2012; 30:4558-4565.

35. Russell MM, Ganz PA, Lopa S, Yothers G, Ko CY, Arora A, Atkins JN, Bahary N, Soori GS, Robertson JM, Eakle J, Marchello BT, Wozniak TF, et al. Comparative effectiveness of sphincter-sparing surgery versus abdominoperineal resection in rectal cancer: patient-reported outcomes in National Surgical Adjuvant Breast and Bowel Project randomized trial R-04. Ann Surg. 2015; 261:144-148.

36. Danial NN, Korsmeyer SJ. Cell death: critical control points. Cell. 2004; 116:205-219.

37. Paek AL, Liu JC, Loewer A, Forrester WC, Lahav G. Cellto-cell variation in p53 dynamics leads to fractional killing. Cell. 2016; 165:631-642.

38. Vousden KH, Lu X. Live or let die: the cell's response to p53. Nat Rev Cancer. 2002; 2:594-604.

39. Sun J, Zhang D, Bae DH, Sahni S, Jansson P, Zheng Y, Zhao Q, Yue F, Zheng M, Kovacevic Z, Richardson DR. Metastasis suppressor, NDRG1, mediates its activity through signaling pathways and molecular motors. Carcinogenesis. 2013; 34:1943-1954.

40. Koshiji M, Kumamoto K, Morimura K, Utsumi Y, Aizawa M, Hoshino M, Ohki S, Takenoshita S, Costa M, Commes T, Piquemal D, Harris CC, Tchou-Wong KM. Correlation of $\mathrm{N}$-myc downstream-regulated gene 1 expression with clinical outcomes of colorectal cancer patients of different race/ethnicity. World J Gastroenterol. 2007; 13:2803-2810.

41. Wangpu X, Yang X, Zhao J, Lu J, Guan S, Lu J, Kovacevic Z, Liu W, Mi L, Jin R, Sun J, Yue F, Ma J, et al. The metastasis suppressor, NDRG1, inhibits "stemness" of colorectal cancer via down-regulation of nuclear $\beta$-catenin and CD44. Oncotarget. 2015; 6:33893-33911. doi: 10.18632/oncotarget.5294.

42. Lu WJ, Chua MS, So SK. Suppressing N-Myc downstream regulated gene 1 reactivates senescence signaling and inhibits tumor growth in hepatocellular carcinoma. Carcinogenesis. 2014; 35:915-922.

43. Crowther AJ, Ocasio JK, Fang F, Meidinger J, Wu J, Deal AM, Chang SX, Yuan H, Schmid R, Davis I, Gershon TR. 
Radiation sensitivity in a preclinical mouse model of medulloblastoma relies on the function of the intrinsic apoptotic pathway. Cancer Res. 2016; 76:3211-3223.

44. Miyashita T, Reed JC. Bcl-2 oncoprotein blocks chemotherapy-induced apoptosis in a human leukemia cell line. Blood. 1993; 81:151-157.

45. Emi M, Kim R, Tanabe K, Uchida Y, Toge T. Targeted therapy against Bcl-2-related proteins in breast cancer cells. Breast Cancer Res. 2005; 7:R940-R952.

46. Rooswinkel RW, van de Kooij B, de Vries E, Paauwe M, Braster R, Verheij M, Borst J. Antiapoptotic potency of $\mathrm{Bcl}-2$ proteins primarily relies on their stability, not binding selectivity. Blood. 2014; 123:2806-2815.

47. Vier J, Groth M, Sochalska M, Kirschnek S. The antiapoptotic Bcl-2 family protein A1/Bfl-1 regulates neutrophil survival and homeostasis and is controlled via PI3K and JAK/STAT signaling. Cell Death Dis. 2016; 7:e2103.

48. Breitschopf K, Haendeler J, Malchow P, Zeiher AM, Dimmeler S. Posttranslational modification of Bcl-2 facilitates its proteasome-dependent degradation: molecular characterization of the involved signaling pathway. Mol Cell Biol. 2000; 20:1886-1896.

49. Dong Y, Zheng Y, Xiao J, Zhu C, Zhao M. Regulatory effect of Bcl-2 in ultraviolet radiation-induced apoptosis of the mouse crystalline lens. Exp Ther Med. 2016; 11:973-977.

50. Dimmeler S, Breitschopf K, Haendeler J, Zeiher AM. Dephosphorylation targets Bcl-2 for ubiquitin-dependent degradation: a link between the apoptosome and the proteasome pathway. J Exp Med. 1999; 189:1815-1822. 